\title{
Out of Control: Growth and Indirect Discrimination in Ada and Canyon Counties' Rental Processes
}

\author{
Berit Schaus ${ }^{1}$, Sharon Hanson" ${ }^{\#}$ and Timothy Thomas ${ }^{\#}$ \\ ${ }^{1}$ Boise High School, Boise, ID, USA \\ \#Advisor
}

$\underline{\text { ABSTRACT }}$

Minimal research has been done on race in evictions and the rental process, and those studies that have been performed have been limited to narrow geographical regions (Thomas, 2017; Desmond, 2016). Additionally, research hasn't been extended to Idaho, a state that is recognized for its rapid population growth. Research on evictions' impact on New Americans is essentially nonexistent. Employing the Naïve Bayes Model, a modification of the Naïve Bayes Model, and content analysis of interviews, this study sought to uncover the impact of racial discrimination and growth in the eviction process. The results proved that black and Latinx minorities are evicted at higher rates than their white and Asian counterparts and that a lack of tenant protections and rapidly increasing housing prices, among other things, have played pivotal roles in Idaho's eviction rates, specifically of racial minorities.

\section{Literature Review}

Housing deprivation, the condition in which housing is unable to meet peoples' basic needs, can lead to a variety of problems in people's everyday lives. These conditions include disproportionately high housing prices, cramped living conditions, and inadequate neighborhoods (Foley, 1980). Large families may be unable to afford an apartment large enough to accommodate everyone, and some apartments house more than one family. This can lead to rapid spread of illnesses and a low quality of life for those unable to afford appropriate housing. Since the mid to late 1970s, housing prices in the United States have risen rapidly, causing people to pay larger amounts of money for smaller and less adequate housing (Foley, 1980). Those that could once barely afford housing that satisfied their needs now find it impossible to afford rent at all. In the last 20 years, most states have seen a 50 to $100 \%$ increase in average housing costs, with some states, such as California, seeing more than a 200\% increase (Routley, 2020), which has led to a higher number of people unable to afford the same houses and apartments that they would have been able to pay for just a few years ago. People employed at jobs once considered to have good salaries no longer have their basic needs met, this is exacerbated by the income gap, which generally impacts minority groups. Known for his work on housing discrimination, Douglas Massey, a professor of sociology at Princeton University, explains the history of housing discrimination in "American Apartheid: Segregation and the Making of the Underclass" (1990). According to Massey (1990), the emergence of large income and wealth gaps paralleled rapid increase in housing prices, leading to a distinct middle and lower class. Due to gentrification, the improvement of a neighborhood previously considered undesirable by the middle and upper classes, and discrimination, the burden of increasing poverty is left to fall on the already often struggling lower class (Massey, 1990). This means the lower class is no longer able to afford rents in areas of the city previously considered undesirable to the middle and upper classes. Through gentrification and higher housing prices, they are forced to move out of the neighborhoods they previously lived in, having to bear the financial and social problems that come with relocating. Additionally, in highly segregated cities and neighborhoods, the burden of raising housing prices is more likely to fall on black people than on white people. Taking a city highly segregated by both socio-economic standing and race, nearly all the burden of rising poverty rates will fall on poor black neighborhoods (Massey, 1990). The issue of the income gap and housing inequality is a constant feedback loop, with the income gap 
emerging as a result of housing and income inequality exacerbating housing issues. Low wages and high housing prices lead to spending a disproportionate amount of income on rent, a condition known as rent burden.

In 1991, the number of renting families spending more than $30 \%$ of their income, the general benchmark for a rent burdened household, grew, despite the number of people renting homes increasing (Desmond, 2018). Matthew Desmond, a professor of Sociology at Harvard, has attributed this to decreasing wages coupled with increasing housing prices (Desmond, 2012). As people earn less but pay more for housing, they are devoting larger percentages of income to housing. Families struggling to afford to pay for everything have to choose between necessities, a decision no one wants to make for themselves or their children. In general, families feel they can pay for smaller costs, for example keeping the heat on, in full and pay their landlord a portion (or none) of the rent. This decision, however, comes with a cost. Failure to pay rent is the highest indicator of whether a tenant will be evicted or not (Desmond, 2012). As a result of the income gap, black and Hispanic families are at increased risk of spending higher percentages of income on housing (Desmond, 2018), but they also may be evicted for reasons other than their inability to pay rent.

Discrimination is an issue that has impacted eviction rates in major cities, including Seattle in King County, Washington. A study conducted by a PhD student at University of Washington, Dr. Timothy Thomas, discovered Black and Latinx people (people of Latin American descent) had an increased risk of being evicted, having an eviction rate seven times higher than their white counterparts (Thomas, 2017). While this data doesn't necessarily indicate causation, it does bring forth questions about why minority groups have higher eviction rates. This could be explained by the income gap, but it could also indicate inherent bias held by landlords. Landlords hold the power to evict tenants, whether formally or informally, and play a large role in housing security for people renting from them, no matter the race of the tenants. The private housing market leaves room for landlords to make judgements on who to evict. Prejudices, such as racism, are correlated with evictions of black and Latinx people.

The causes of changing eviction rates have been studied in many areas around the United States, including King County, Washington and Milwaukee, Wisconsin. General research on eviction rates in Idaho has been done by Boise State University and the Princeton Eviction Lab, and show differences in eviction rates between individual years, up to 2017, but no extensive research has shed light on specific characteristics of Ada and Canyon counties that contribute to a growing eviction rate. Ada County is home to the city of Boise, named the fastest growing city in the U.S. between 2017 and 2018 (Warren, 2019), causing increased housing and rent prices; the researcher hypothesizes that there will be other factors connected to growth that contributed to increased eviction rates. Research on race in evictions has been limited to King County and Milwaukee, but the demographics of these areas are vastly different than Idaho. Ada and Canyon Counties are majority white with their largest minority groups being Latinx. Milwaukee is majority black, and King County is majority white with the largest minority population being Asian, leaving a gap in how minorities living in areas with high numbers of Latinx people and low numbers of black individuals are impacted by eviction. Latinx people comprise $8.51 \%$ and $25.67 \%$ of Ada and Canyon counties, respectively (U.S. Census Bureau). According to research done by Dr. Timothy Thomas (2017), Latinx people were discriminated against in the eviction process in King County, Washington, making the studying of evictions' effects on the Latinx population in Ada and Canyon Counties in Idaho intriguing. Furthermore, to date, there has been no extensive research done on the impact evictions have on new Americans. One study performed evaluated cultural differences between Samoans and Native Hawaiians in Hawaii and how that may lead to eviction, but it didn't cover discrimination faced by these groups, only what a court would accept as a valid reason to not pay rent (Lempert \& Monsma, 1994). Idaho ranked 3 rd in the nation for the number of refugees resettled per capita in 2016, making counties in Idaho ideal for studying how new Americans are impacted by evictions (Radford \& Connor, 2016). This begs the question: How did rapid population growth and potential discrimination in the eviction process impact citizens, specifically Latinx, black, and new American individuals, in Ada and Canyon counties in Idaho in 2018? 


\section{Methods}

In order to evaluate discrimination against Latinx, black, and new American individuals, along with growth, a 3-part, mixed method approach was applied. Content analysis was employed alongside the use of the Naive Bayes model, which calculates the probability someone is a certain race based on their last name and geolocation.

\section{Racial Estimation}

To determine racial discrimination in the eviction process, eviction records and cases were compiled. A complete list of all eviction records from 2018 in Ada and Canyon counties were obtained from the Idaho Supreme Court website through a data request form. The Ada County Clerk's office provided computer kiosks where the complete record of all scanned court documents could be accessed by case number. Content analysis was performed on the corresponding records to find the name of the plaintiff and defendant as well as the address of the property where the eviction occurred and the result of the case. All this information was compiled within a spreadsheet. Using the R package 'tidycensus,' each address was geocoded (see Appendix A).

The Naïve Bayes model depended on the information within the spreadsheet to estimate race which was crucial because citizens' individual races are unavailable in Idaho's public records. In order to get a sense of the race of evictees, Thomas's (2017) technique of racial estimation was used. This technique used first and last names of evicted tenants combined with social security data, census tract data, and the Naive Bayes model in order to get the most likely race of the evicted tenant. The Naive Bayes model used these statistics and combined them to then determine an individual tenant's probable race.

\section{The Use of Naive Bayes Model}

The Naive Bayes Model is a model traditionally used to determine the probability of an individual's race based on their surname and geolocation of the address at which they live (Imai and Khanna, 2016). The individual is represented as $i$ with the surname, geolocation and race of the individual being represented as $S_{i}, G_{i}$, and $R_{i}$, respectively (Imai and Khanna, 2016). Surnames, geolocation and race without association with a particular individual are denoted as $s$, $g$, and $r$, respectively (Imai and Khanna, 2016). The racial composition of a given geolocation is shown as $\operatorname{Pr}\left(R_{i}=\right.$ $\left.r \mid G_{i}=g\right)$, the racial composition of a given surname is given as $\operatorname{Pr}\left(R_{i}=r \mid S_{i}=s\right)$, and the demographics of a geolocation is represented by $\operatorname{Pr}\left(G_{i}=g\right)$ (Imai and Khanna). This leads to the equation:

$\operatorname{Pr}(R \mathrm{i}=r \mid S \mathrm{i}=s, G \mathrm{i}=g, X \mathrm{i}=x)=\frac{\left(\operatorname{Pr}(G \mathrm{i}=g, X \mathrm{i}=x \mid R \mathbf{i}=r) \operatorname{Pr}\left(R \mathrm{i}=r \mid S_{\mathrm{i}}=s\right)\right)}{\sum_{r^{\prime} \in R} \operatorname{Pr}\left(G \mathrm{i}=g, X \mathrm{i}=x \mid R \mathrm{i}=r^{\prime}\right) \operatorname{Pr}\left(R \mathrm{i}=r^{\prime} \mid S \mathrm{i}=s\right)}$

Dr. Timothy Thomas, who served as an expert advisor, had this equation programmed into an $\mathrm{R}$ package and he was able to run the equations on the compiled spreadsheet. Thomas used this estimation technique in his dissertation examining discrimination in evictions in Seattle, which was focused on gender discrimination and discrimination against the black and Latinx populations of Seattle (2017). The Naive Bayes Model already programmed in his computer was able to provide data on the race of evicted tenants. This methodology was the most fitting for the nature of this study as it allowed for additional information to be deduced from the information available within public records. An ethnographic study or a survey method would not have been able to cover as large of a sample size, limiting the perspective that could be gained. Furthermore, the issue of losing stable housing and having financial problems is a taboo, and often difficult subject, that would have presented issues with ethicality if a survey or ethnographic study were conducted. 


\section{Modification of the Naive Bayes Model}

As aforementioned, analysis of evictions' impacts on new American communities have yet to be analyzed in depth. Dr. Thomas's employment of the Naive Bayes model was meant to determine race at an individual level but did not predict individual ethnicities or citizenship/new American status. Nevertheless, the concept behind the Naive Bayes model was able to be applied in a different way to determine correlation between new American status and eviction rates. Addresses had previously been derived from public records in the Ada County Courthouse (which also gave access to Canyon County public records).

A designated column in the spreadsheet contained the census tract number for each address, determined through The Federal Financial Institutions Examination Council's geocoder. The percentage of evictions that occurred in each census tract was calculated for Ada and Canyon counties. Using the U.S. Census Bureau's website, data on foreign born population and time of entry into the U.S. was accessed (see Appendix B for specific filters and a visual of the table). This part of the study was designed to determine the impacts evictions could potentially have on new Americans, who would have to be foreign born (thus the foreign-born criteria) and 'entered after 2010' was chosen because it was the most recent estimate that would qualify a 'new' American, as opposed to people that have lived in the U.S. for an extended period. In this case, the longest someone would have been living in the U.S. would have been eight years as estimates were obtained from 2010 and the study used eviction records from 2018. The percent of the foreign-born population and the percent of that population that entered the U.S. after 2010 from a specific census tract were recorded in a table. To determine what percentage of the tract would be foreign born and have entered after 2010, the two percentages were multiplied, thus offering an estimate of what percentage of the tract was 'new American' in both Ada and Canyon counties.

Once these percentages were calculated, the Pearson correlation test in Microsoft Excel was run to determine correlation between the foreign-born population and evictions as well as the new American population and evictions. This was done separately for Ada and Canyon counties and the numbers of evictions of foreign born and new Americans were combined to determine overall correlation.

\section{Content Analysis}

Content analysis was performed on interviews conducted with four separate agencies and individuals in Ada County. Two non-profit organizations, one former Idaho Supreme Court justice, and a landlord/real estate agent were contacted to gain various perspectives. Jesse Tree, a nonprofit organization, works to prevent evictions and was chosen for their perspective on causes behind evictions. Jesse Tree has been working with evictions since 1999, allowing them to observe the impact Ada County's growth has had on eviction. The second non-profit, Agency for New Americans, is one of Ada County's leading organizations assisting in the resettlement of new Americans. Their perspective on issues new Americans face when renting was valuable in answering remaining questions about discrimination present against new Americans in the eviction process. To form a comprehensive picture of the issues presented by eviction, a real estate agent, who also manages his own properties as a landlord, provided insight into factors that have arisen from Idaho's rapid growth, potentially contributing to eviction. Finally, the perspective of a former Supreme Court justice provided a broad, legal perspective stemming from the wide range of cases he has dealt with during his career. He was chosen to provide a perspective on trends in eviction that specifically impact Ada and Canyon counties, and his pro bono work with refugee families in Ada County qualified him to speak on the topic of eviction's effect on new Americans.

The content analysis was inductive and aimed to answer the growth aspect of the research questions which wasn't addressed by the Naïve Bayes Model. Interview questions were developed based on the two main parts of the research question: growth and discrimination. The interviewees were asked questions to guide the discussion, but indepth discussion of the question, as well as related topics, was not interrupted. The interviews were recorded, and key words related to growth, discrimination, and eviction problems specific to Idaho were coded for within each of the recorded interviews. These words were later grouped into categories, which will be further discussed in the results 
section. Three out of six of the questions were kept the same for all four interviews, with the last three differing slightly based on the interviewee's unique experience and perspective on varying aspects of the research question. The specific interview questions can be found in Appendix $\mathrm{C}$.

The precedent for qualitative reporting on eviction was largely set by Matthew Desmond in his book "Evicted: Poverty and Profit in the American City" (2016). Desmond mainly focused on gaining the perspective of landlords and tenants throughout his book, looking to see issues with evictions and serving evictions through the court system. Rather than conducting sit down interviews, Desmond's study was ethnographic, following the tenants and landlords through the variety of interactions that led to eviction. This was not feasible for the conducted study due to time constraints and safety concerns with Covid-19. However, conducting interviews with a property management company mimicked shadowing a landlord, and organizations that could speak on general trends on behalf of their clients were determined to be the best method to gather the perspective of a tenant.

\section{Results}

\section{Racial Estimation}

As a result of the first and last names as well as geocoded addresses being analyzed using the Naive Bayes model, numbers and percentages of the different races of evictees were determined. The raw numbers of how many people from each gender and race, without any performed calculations, can be seen in Figure 1.

\begin{tabular}{|l|l|l|l|l|}
\hline & \# Black & \# White & \# Latinx & \# Asian \\
\hline Ada & 164 & 737 & 136 & 17 \\
\hline Canyon & 14 & 314 & 152 & 2 \\
\hline Ada and Canyon & 178 & 1051 & 288 & 19 \\
\hline
\end{tabular}

Figure 1. Racial demographics of evictees from Ada and Canyon counties in 2018.

\section{Effect of New American Status on Eviction}

Figure 2 shows the county, demographic, and the calculated correlation coefficient between those 2 variables.

\begin{tabular}{|l|l|l|}
\hline County & Demographic & Correlation Coefficient \\
\hline Ada & Foreign born & 0.272436 \\
\hline Canyon & Foreign born & 0.411385 \\
\hline Ada and Canyon & Foreign born & 0.281784 \\
\hline Ada & New American & 0.292088 \\
\hline Canyon & New American & 0.036277 \\
\hline Ada and Canyon & New American & 0.25654 \\
\hline
\end{tabular}

Figure 2. Correlation between foreign born/new American populations and eviction rates.

When determining the corresponding census tracts of addresses, 53 of the total addresses $(3.446 \%$ of the total cases) were unable to be found. These numbers are not represented in this data. 


\section{Growth's Impact on Evictions in Ada and Canyon Counties}

Figure 3 shows the inductive coding developed from the four interviews performed with varied organizations within Ada County, Idaho. The number of interviews that illustrated each of these themes are included.

\begin{tabular}{|c|c|}
\hline Themes and Sub-Themes & \# of Interviews Containing Theme \\
\hline 1. Movement from out of state & 2 \\
\hline 2. High demand and low supply & 4 \\
\hline 3. Low wages & 4 \\
\hline 4. Purchasing of inventory by investors & 2 \\
\hline 5. Strained tenant-landlord relationships & 3 \\
\hline $\begin{array}{l}\text { 6. State and local government policies } \\
\text { Renter protection laws } \\
\text { Zoning laws }\end{array}$ & 2 \\
\hline $\begin{array}{l}\text { 7. Discrimination } \\
\text { Racism } \\
\text { Classism } \\
\text { New Americans }\end{array}$ & 4 \\
\hline 8. Language barrier & 2 \\
\hline $\begin{array}{l}\text { 9. New Americans lack understanding of housing poli- } \\
\text { cies }\end{array}$ & 2 \\
\hline
\end{tabular}

Figure 3. Inductive coding of interviews.

Figure 4 provides quoted evidence from the performed interviews to support the developed themes.

\begin{tabular}{|l|l|}
\hline Code number & Quoted Evidence from Interview Transcripts \\
\hline 1 & $\begin{array}{l}\text { 'One of the things that led to the tight inventory was probably more people from out of state } \\
\text { moving in [...].' (Interview with Landlord) }\end{array}$ \\
\hline 2 & $\begin{array}{l}\text { 'Given the high need of housing in the area, [property managers] just give you an eviction } \\
\text { knowing the next day, or the next few hours, they're going to have somebody else moving in.' } \\
\text { (Interview with Agency for new Americans) } \\
\text { 'Hitting the increased demand, reduced supply [...].' (Interview with Landlord) }\end{array}$ \\
\hline 3 & $\begin{array}{l}\text { 'Idaho wages are much lower than comparable markets. If you compare us to Salt Lake or } \\
\text { Portland or Seattle where we are the little guys, our wages are much lower and our house } \\
\text { [prices] are only a little bit lower.' (Interview with Landlord) }\end{array}$ \\
\hline
\end{tabular}




\begin{tabular}{|c|c|}
\hline 4 & $\begin{array}{l}\text { 'Large property companies entered the market when the prices of houses and apartment units } \\
\text { dropped [during the } 2008 \text { recession] and bought substantial numbers knowing that prices } \\
\text { would eventually rise.' (Interview with Landlord) } \\
\text { 'The primary buyers of homes in Canyon County were investors, so they're buying the houses } \\
\text { and renting them out.' (Interview with Landlord) }\end{array}$ \\
\hline 5 & $\begin{array}{l}\text { 'While landlords were generally familiar with their tenants and were willing to work with them } \\
\text { on payment, repair and other issues, the corporate property managers were more impersonal } \\
\text { and less caring.' (Interview with Supreme Court justice) }\end{array}$ \\
\hline $6 a$ & $\begin{array}{l}\text { 'I own residential properties in Seattle, and there are lots and lots and lots of rules and renters } \\
\text { rights there that, they make it a lot more restrictive than here.' (Interview with Landlord) } \\
\text { 'Idaho is very much a pro-landlord state.' (Interview with Jesse Tree) }\end{array}$ \\
\hline $6 \mathrm{~b}$ & $\begin{array}{l}\text { 'So, this neighborhood, that [house across the street] wouldn't be allowed to be built today, } \\
\text { this [house next door] wouldn't be allowed to be built today, because they're multi-family } \\
\text { houses in single family zones. The history of that zoning is mostly people sitting around saying } \\
\text { 'How do we keep the black people out?' That's, it's also rich people saying 'How do we keep } \\
\text { the poor people out?' but, it's all tied up in 'How do we keep the riff raff out?'' (Interview } \\
\text { with Landlord) }\end{array}$ \\
\hline $7 \mathrm{a}$ & $\begin{array}{l}\text { 'I've had, recently I had a case where I feel like, you know, discrimination was at play in this } \\
\text { case. I had to talk to somebody, a lawyer, who helped to resolve this issue but it was mainly, } \\
\text { I think it was racism because, you know, this tenant always brought issues to the management } \\
{[\ldots . .] \text {. [...] it's really a challenge and I don't know how to overcome that and, especially people }} \\
\text { of color.' (Interview with Agency for New Americans) }\end{array}$ \\
\hline $7 \mathrm{~b}$ & $\begin{array}{l}\text { '[The zoning laws] are an implicit government bias against who?' } \\
\text { 'People who can't afford to buy a house.' } \\
\text { 'Right? It's like well why, you don't hear people say that that's immoral. We just live with it.' } \\
\text { (Interview with Landlord) }\end{array}$ \\
\hline $7 \mathrm{c}$ & $\begin{array}{l}\text { 'There is an element, working with new Americans and refugees, they get taken advantage of. } \\
\text { It's not uncommon, I've represented refugees on landlord-tenant issues and they are unaware } \\
\text { of the specifics of the court system. They don't know how to get a lawyer or they'll miss their } \\
\text { hearing and get a default judgement.' (Interview with Agency for New Americans) }\end{array}$ \\
\hline 8 & $\begin{array}{l}\text { "And, you know, the other thing though is, to be honest, when you, for example, when some- } \\
\text { body is signing the lease, the whole package is in English and, you know, these folks, they } \\
\text { don't speak English." (Interview with Agency for New Americans) }\end{array}$ \\
\hline 9 & $\begin{array}{l}\text { 'I think that what drives these evictions are mostly, of the refugee population, is mostly a } \\
\text { language barrier because most of the time, clients won't understand the housing policies and } \\
\text { the guidelines and, you know, in the end, they kind of find themselves breaking the law.' } \\
\text { (Interview with Agency for New Americans) }\end{array}$ \\
\hline
\end{tabular}

Figure 4. Quoted evidence to support inductive coding from Figure 3. 


\section{Discussion}

The results yielded from the use of the traditional methodology of the Naive Bayes model revealed significance of which races were evicted at higher rates. Figure 6 shows a comparison between the racial demographics of Ada County and the racial demographics of evictees in Ada County.

\section{Ada County Demographics}

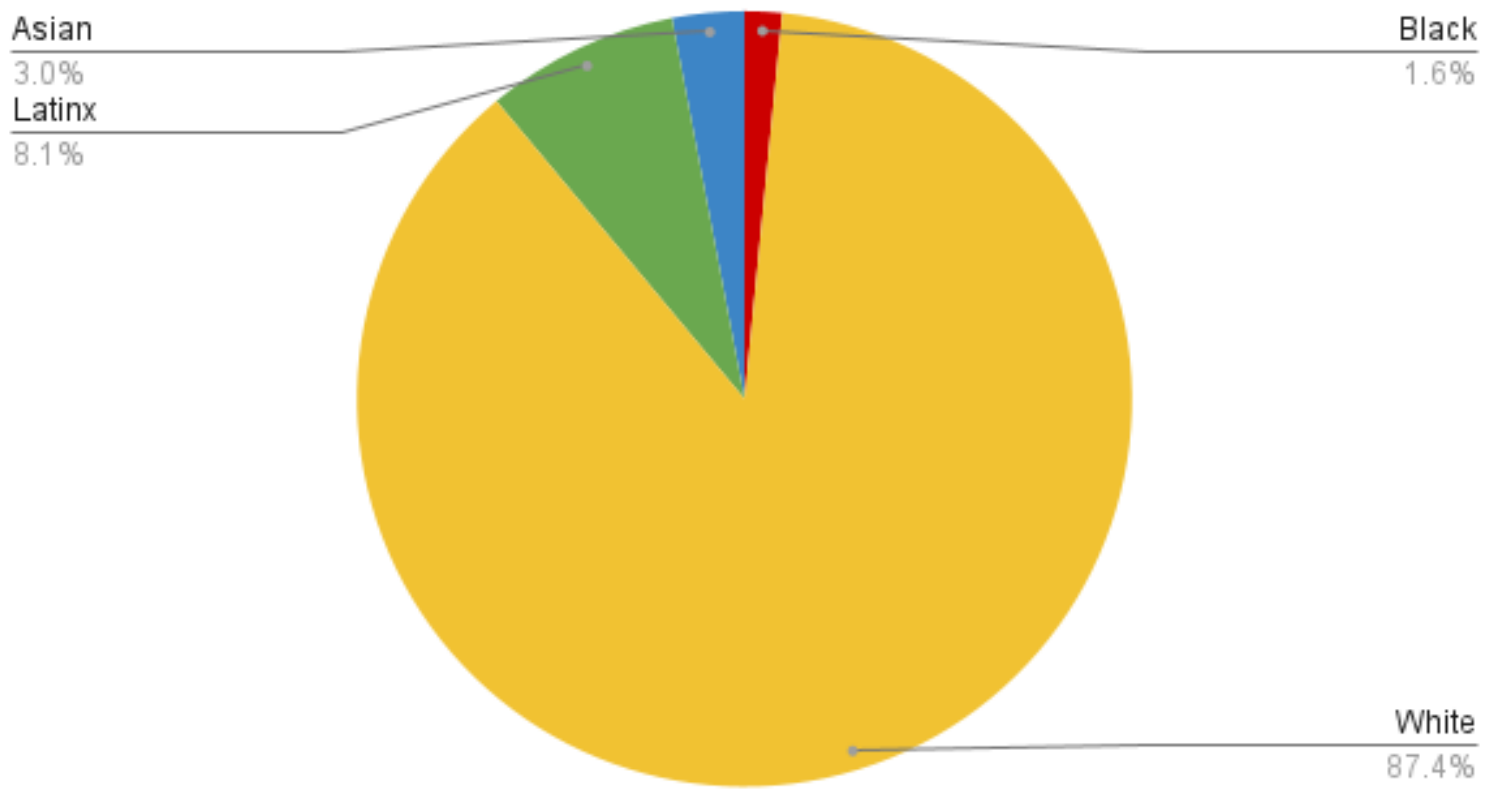

Figure 5. Demographics of Ada County. 


\section{Demographics of Evictees in Ada County}

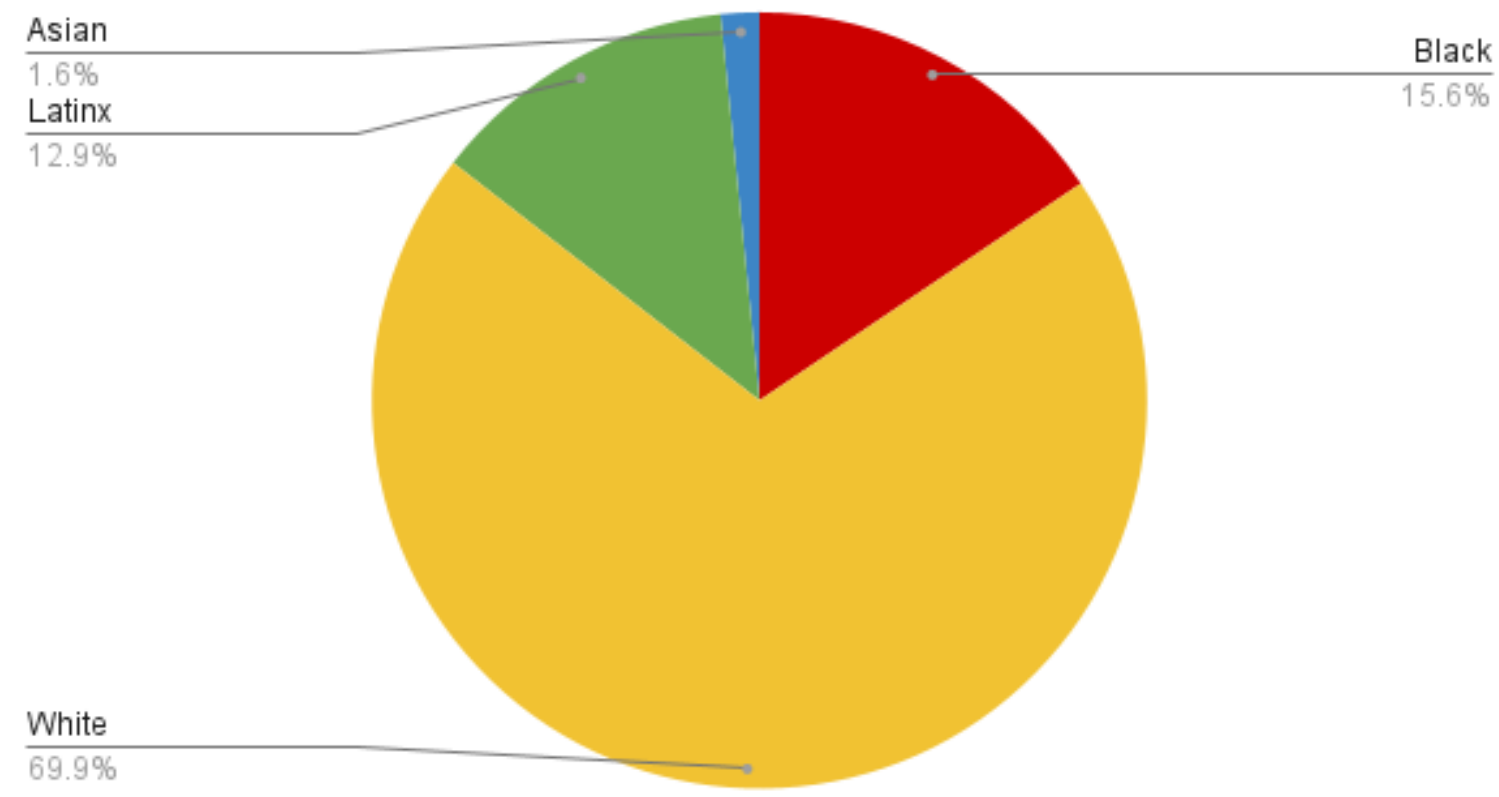

Figure 6. Demographics of Evictees in Ada County.

As shown in the figures, there were discrepancies between the percentage of Ada County made up by black and Latinx people and the percentage of evictions made up by these same groups. Ada County is $1.6 \%$ black and $8.1 \%$ Latinx, whereas $15.6 \%$ of evictions in 2018 were of black people and $12.9 \%$ were of Latinx people. Black people were evicted at a rate roughly 15 times higher than Ada County's demographics would suggest. Given the small black population residing in Ada County to begin with, it is safe to say there was a correlation between people being black and people being evicted at a higher rate than their white or Asian counterparts in 2018. While Latinx people's eviction rate was not as stark of a contrast, they were still evicted at a higher rate than their percentage of Ada County's population would suggest. Latinx individuals were evicted at a rate about 1.6 times higher than would be expected, given their relative proportion of Ada County residents.

Figures 7 and 8 show the demographics of Canyon County and the demographics of evictees in Canyon County in 2018. 


\section{Demographics of Canyon County}

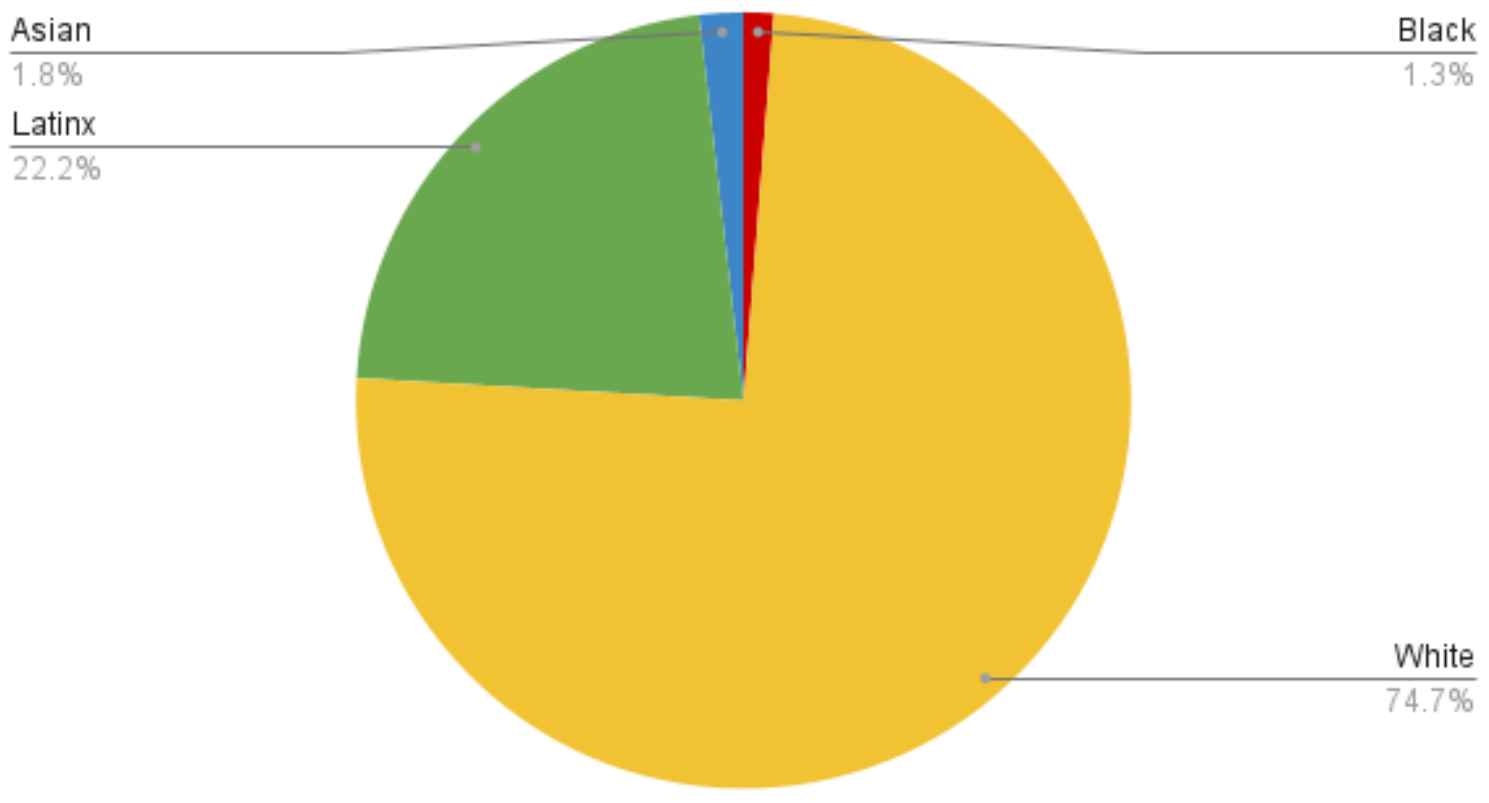

Figure 7. Demographics of Canyon County.

\section{Demographics of Evictees in Canyon County}

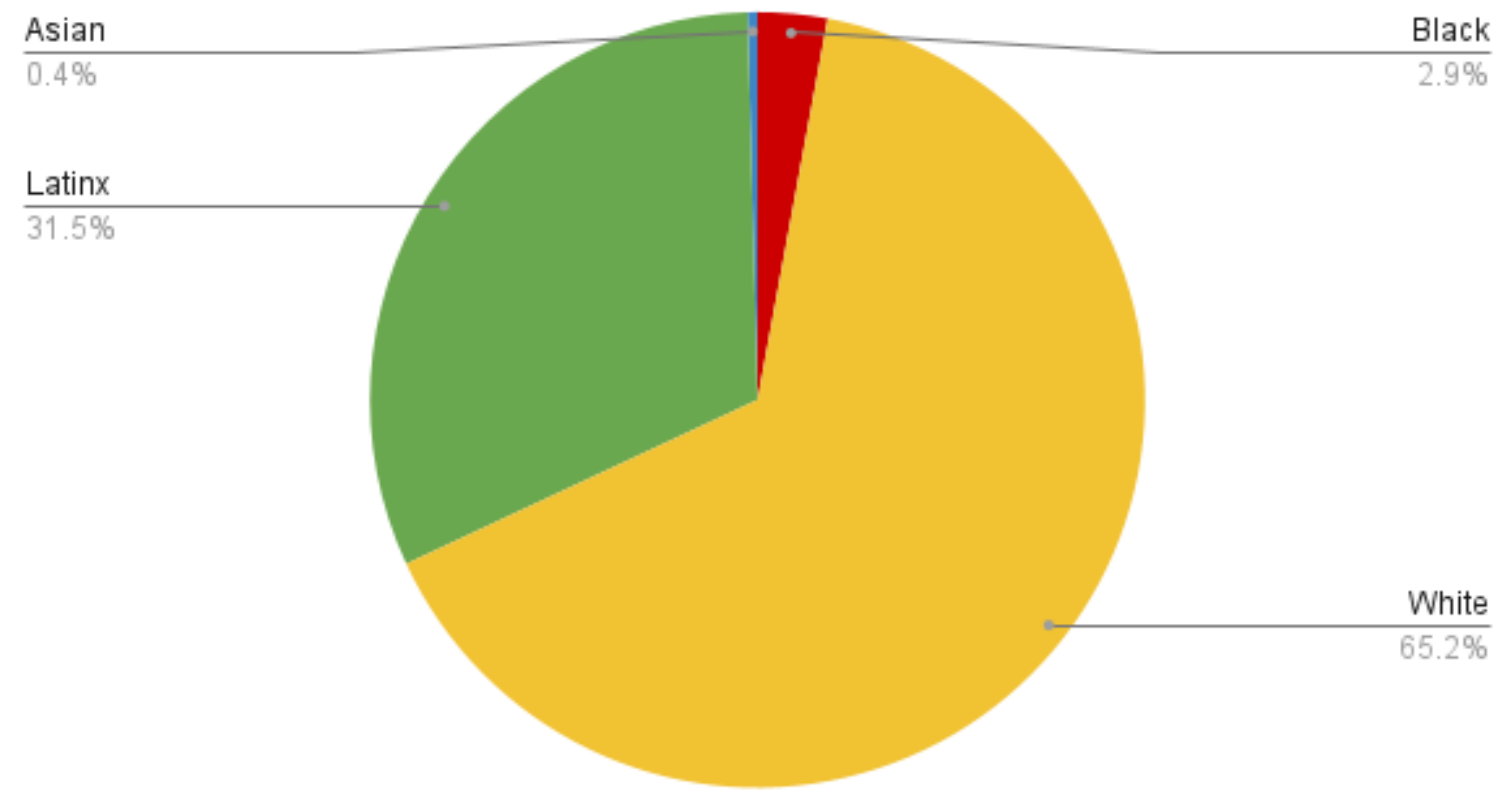

Figure 8. Demographics of evictees in Canyon County.

As shown in Figures 7 and 8, the demographics of evictees in Canyon County were much closer to what would be expected given the demographics of the entire county. Latinx people make up $22.2 \%$ of Canyon County but 
were the evictees in $31.5 \%$ of Canyon County's eviction cases in 2018. Latinx people were evicted at a rate 1.4 times higher than would be expected, suggesting there was a correlation between being Latinx and experiencing a higher eviction rate. Black people were also evicted at rates inconsistent with what would be expected, with an eviction rate of $2.9 \%$ while comprising $1.3 \%$ of the total population, meaning they were evicted at a rate 2.2 times higher than would be expected. There was a correlation between Latinx, and black people being evicted more frequently than predicted based on the racial composition of Canyon county. The results indicate a correlation between Latinx and black individuals and increased rate of eviction, however, the eviction rate/demographic discrepancy for black people in Canyon county was not as stark as Ada county.

Figure 2 showed the correlation coefficients calculated between foreign born and new American populations and evictions in Ada and Canyon counties. A correlation coefficient of 0 indicates no correlation whereas a correlation coefficient of 1 indicates a perfect linear relationship. None of the correlation coefficients were above 0.5 , indicating there was no positive correlation between new American or foreign-born individuals being evicted at a higher rate than native born individuals. These results indicate that there is no correlation between individuals being new American and these same individuals being evicted at higher rates. As such, it can be concluded that there is no evidence of direct, continued, widespread discrimination against new Americans in the eviction process.

\section{Lack of Affordability}

Codes 1 through 4 all compose aspects of a lack of affordability that has developed in Ada and Canyon counties following the population growth seen by these areas. Code 1 was developed based on interviews that mentioned movement from out of state which has contributed to growth. In addition to movement within state and natural population growth that occurs as more children are born, movement from out of state has sped up this growth. According to the U.S. Census Bureau, 80,000 people moved to Idaho from out of state in 2018 (Census Bureau, 2018) and this has contributed to high housing demand seen in Ada and Canyon counties. Code 2 was developed to demonstrate the supply demand issues currently facing the Boise area. Out of state movement has contributed to population growth, meaning more people need housing. The high demand has led to houses on the market being bought quickly and, as houses take time to build, the supply of housing in Ada and Canyon counties has not expanded to meet the demand faced in the area. Furthermore, investors have been buying housing inventory, knowing the market values of Ada and Canyon county homes have increased dramatically, with Ada County's housing prices having tripled since 2011 (Ramey, 2021). Additionally, Idaho has comparatively low wages when compared to other cities and states with similarly high housing prices, as mentioned or referenced in all four of the conducted interviews. The growth that has occurred and been exacerbated by movement from out of state has led to a high demand for housing, which the supply has been unable to accommodate. As such, it stands to reason that the high demand for the low supply is connected to the increasing housing prices in the Treasure Valley. Idaho's low wages do not allow for people, specifically those working minimum wage jobs or who make a moderate income, to afford the increased prices being seen in both counties. If someone is unable to afford to pay rent given that prices have increased and wages are too low to accommodate this price increase, that person will likely be evicted. This can be seen as especially relevant given, as stated in the literature review, failure to pay or afford rent is the strongest predictor of who will be evicted (Desmond, 2012).

\section{Social and Relational Issues}

Codes $6,7 \mathrm{a}$, and $7 \mathrm{~b}$ were more representative of social and relational issues facing people in the Treasure Valley. While some of them may be connected to growth and the other factors contained in codes 1 through 5 , they are mainly issues developed throughout the interviews as discrimination or government related themes. Codes $6 \mathrm{a}$ and $6 \mathrm{~b}$ represent renter protection and zoning laws, which have caused problems for renters in the Boise area. Cities that are comparable price wise, such as Seattle and Portland, have more renter protection meant to prevent excessive eviction. For example, Seattle's Just Cause Eviction Ordinance prohibits landlords from evicting a tenant without that tenant having broken 
one of eighteen rules outlined by the City of Seattle (Seattle Department of Construction and Inspections). In accordance with Washington state law, a trail to prove cause for eviction must be held in order to proceed with an eviction case. In Idaho, this same law is not applicable, meaning the cause of the eviction doesn't necessarily have to be proven in order to evict someone (Steven, 2013-2014). Idaho's zoning laws are similar to many other states in that they do not allow the mixing of multi-family and single-family homes within a given housing zone. While these laws are widespread, with most American cities having 75\% of residential land devoted to single family zones, cities such as Minneapolis and states including Oregon and California have considered ending zone segregation ((Badger and Bui, 2019). Given the high housing demand in the Boise area, having a large percentage of the residential land devoted to single family homes further restricts the supply as a plot of land that could have multiple residences is only allowed to have one. Historically, these policies also tend to be racist and classist (codes $7 \mathrm{a}$ and $7 \mathrm{~b}$ ). $74.5 \%$ of housing in the United States is owned by non-Hispanic white people, and, given housing prices and credit scores needed to get a mortgage, most renters are non-white, low-income individuals. Zoning laws restrict low income, more affordable housing that would be available to these groups and the high prices that have been exacerbated by the Boise area's growth make it even more difficult to find affordable housing.

\section{Hardships Faced by New Americans}

Codes 7c, 8, and 9 showed hardship faced by new Americans when facing eviction. Along with potential direct discrimination facing this group of people, policies and standard practices tend to indirectly discriminate against new Americans. The representative from Agency for New Americans and the former Supreme Court Justice identified language barrier and lack of understanding as a disadvantage for new Americans, as many don't speak English as their first language. This language barrier can contribute to confusion when communicating with landlords or when signing a lease, making it difficult for new Americans that are renting to understand the nuances of the conversations they're having or the leases they're signing. Furthermore, housing laws and policies vary among countries and people that have just moved to Idaho from another country find themselves unaware of the legal responsibilities they have once signing a lease. This can lead to confusion, and, especially if they have signed a lease, new Americans may be held legally accountable for a document they signed even if they didn't understand the agreement.

\section{Conclusion}

Based on the findings of this study, it is evident that black and Latinx individuals, new Americans, and people in both Ada and Canyon counties face difficulties. The results derived from the Naive Bayes model clearly indicate that, while race doesn't necessarily cause individuals to be evicted, these individuals are being evicted at a higher rate. The wage gap between white people and black and Latinx people may contribute to black and Latinx individuals having trouble affording housing. A lack of lingual accessibility for non-native English speakers puts people at risk of violating a lease or rental agreement that wasn't understood in the first place, despite there being no positive correlation between someone qualifying as new American and those same people having higher eviction rates.

For residents of Ada and Canyon counties, the growth over the past few years raises questions about the future of the housing market. As people continue to move to Idaho, housing demand will increase, and the supply of housing will continue to be insufficient to fill the demand. Should wages remain stagnant, average people will be forced to move further away from the area's population center as a result of an inability to pay for their living accommodations, be it a house or an apartment. This process of urban displacement will cause mass upheaval of lives, forcing families to begin their lives over again. Children will have to enroll in new schools and make new friends as a result of skyrocketing housing prices. Parents may be forced to find new jobs, as most jobs are concentrated in Ada and Canyon counties. Eventually, it will make little sense for people to commute to their jobs closer to the city center, as the only affordable housing may be over an hour away from their place of employment. 
In the future, investigation of other areas like Ada and Canyon counties that have experienced rapid population growth is paramount to determine more implications growth can have on evictions. Other cities that consistently appear on lists alongside Boise and Meridian, two rapidly growing cities in Ada County, are Frisco, Texas and Buckeye, Arizona (Census Bureau). Furthermore, more research needs to be performed in the area of how evictions impact new Americans. While numerical results didn't indicate correlation, qualitative data revealed that new Americans are put at a disadvantage in the eviction process. Black people and Latinx people were at a higher risk of being evicted in Ada and Canyon counties than their white counterparts, which corroborates Dr. Thomas's (2017) findings from King County, Washington. It is paramount that this is explored in cities nationwide, as it is possible that black and Latinx people are facing housing disadvantages not experienced by white and Asian people.

Future implications for Ada and Canyon county as well as cities nationwide include policy changes to protect renter rights and racial minorities. Idaho's lack of renter protection is detrimental to tenants and contributes to higher eviction rates by not requiring a substantiated claim to evict someone. Ada and Canyon counties' supply of housing, which is already limited by high demand, is worsened by multi-family and single-family zones remaining separate, which restricts the amount of inventory available, as it prevents multiple families from living on an area of land. Ada and Canyon counties already have limited diversity, and racial minorities are put at not only a higher risk of eviction, but also at higher risk of not being able to find housing. The national income gap that exists between races, with black and Latinx people making less on average than white people, coupled with Idaho's low wages for everyone, and high housing prices as caused by demand has made it nearly impossible for people, specifically racial minorities, to afford the post-growth housing in Ada and Canyon counties.

While limitations were mitigated as much as possible, the results of this study were still restricted. Firstly, the racial estimations provided by the Naive Bayes model were just that: estimations. The estimations were based on statistics and probability but, in the end, it is possible that there were white people predicted to be black because of their last name, Latinx people predicted to be white because of their last name, and so on. This limitation would have made the demographics of evictees presented in Figures 6 and 7 slightly skewed, therefore contributing to different results. Furthermore, the racial estimation did not consider individuals that have changed their last name, either post marriage or otherwise, or individuals that identify themselves as bi or multiracial. Both factors could have contributed to inaccurate racial estimations. However, given the nature of inductive coding and the researcher's extensive knowledge on the topic, it is possible that the content analysis portion of the methodology was flawed. In using recorded transcripts and quoted evidence to justify the codes and ensuring that each theme was found within at least two interviews, this limitation was avoided as much as possible. Nevertheless, it is possible that the researcher's own subjective ideas of what the results should have been, or the nature of the interview questions in and of themselves, were biased. Despite the efforts to mitigate this bias, it is important to recognize that inherent bias, from the researcher and the interviewees, was not eliminated.

It is undeniable that the findings of this study are significant to the body of knowledge. This study was able to remedy gaps in the current body of knowledge by investigating potential discrimination against new Americans, supporting Dr. Thomas's (2017) findings, and furthering an understanding of growth's impact on evictions in Ada and Canyon counties. Given the lack of knowledge that existed regarding eviction as a whole in Ada and Canyon counties, it has become evident that population growth contributed to evictions in a number of significant ways and that black and Latinx individuals are at a higher risk of eviction. Furthermore, prior to this study, no extensive research had been conducted on how new Americans were impacted by evictions, but it can now be concluded that, while direct discrimination was not found to be present, indirect policies such as a lack of accessibility to housing materials for non-native English speakers contributes to hardships faced by new Americans. Policy changes are needed, both in Ada and Canyon counties and nationwide, to ensure protection of minority groups in the eviction process and to keep housing affordable for the general population. 


\section{Acknowledgments}

First and foremost, I would like to thank Ms. Sharon Hanson, Ms. Erin Della, and Dr. Timothy Thomas, PhD, for their help and guidance throughout my research project. Without their mentorship, I wouldn't have been able to conduct my research and their commitment to their respective jobs continues to inspire me. They gave me words of encouragement when I needed it the most and believed in me when I didn't always believe in myself. I am beyond grateful for the amount of time and energy that each devoted to helping me complete my work.

I am also grateful to all of the other teachers and faculty at Boise High School that have supported me throughout my academic career. Without the resources and exceptional education that they have all worked to offer me, I would not be where I am today. The openness to curiosity and the environment of respect that each have fostered at Boise High has played a vital role in my ability to excel inside and outside of the classroom and has given me the tools I have needed, and will continue to need, to accomplish amazing things.

I would like to thank my family for their unconditional love and willingness to lift me up in everything I do. Both of my parents work hard to give me and my brother every opportunity we could possibly want, and I am forever appreciative of the sacrifices they make for us. And to my brother, Leo, for his unmatched ability to keep me humble even when I feel as if I could conquer the world.

My gratitude extends to my peers and classmates who spent hours on their own projects and read my paper time and time again, when they never had to. Your commitments to academic and personal excellence set an example for our peers, as well as those older and younger than us.

And, finally, I would like to thank the Boise community and organizations, including The Agency for New Americans and Jesse Tree, for providing me with inspiration for this project. The resilience of our citizens in their daily lives was the driving force behind my curiosity surrounding this issue, and, without our community, the significance of my research would largely disappear.

\section{References}

Badger, E., \& Bui, Q. (2019, June 18). Cities Start to Question an American Ideal: A House With a Yard on Every Lot. Retrieved from https://www.nytimes.com/interactive/2019/06/18/upshot/cities-across-americaquestion-single-family-zoning.html

Bureau, U. C. (n.d.). Census.gov. Retrieved from https://www.census.gov/

Desmond, M. (2012). Eviction and the Reproduction of Urban Poverty. American Journal of Sociology, 118(1), 88133. doi:10.1086/666082

Desmond, M. (2016). Evicted: Poverty and profit in the American city. New York: Crown.

Desmond, M. (2018). Heavy is the House: Rent Burden among the American Urban Poor. International Journal of Urban and Regional Research, 42(1), 160-170. doi:10.1111/1468-2427.12529

Finnigan, R., \& Meagher, K. D. (2018). Past Due: Combinations of Utility and Housing Hardship in the United States. Sociological Perspectives, 62(1), 96-119. doi:10.1177/0731121418782927

Foley, D. L. (1980). The Sociology of Housing. Annual Review of Sociology, 6(1), 457-478. doi:10.1146/annurev.so.06.080180.002325

Imai, K., \& Khanna, K. (2016). Improving Ecological Inference by Predicting Individual Ethnicity from Voter Registration Records. Political Analysis, 24(2), 263-272. doi:10.1093/pan/mpw001

Lempert, R., \& Monsma, K. (1994). Cultural Differences and Discrimination: Samoans Before a Public Housing Eviction Board. American Sociological Review, 59(6), 890. doi:10.2307/2096374

Massey, D. S. (1990). American Apartheid: Segregation and the Making of the Underclass. American Journal of Sociology, 96(2), 329-357. doi:10.1086/229532 
Nelson, G. (2011). Measuring Poverty: The Official U.S. Measure and Material Hardship. Poverty \& Public Policy, 3(3), 1-35. doi:10.2202/1944-2858.1077

Radford, J., \& Connor, P. (2020, August 20). Just 10 states took in 54\% of US refugees in fiscal 2016. Retrieved from https://www.pewresearch.org/fact-tank/2016/12/06/just-10-states-resettled-more-than-half-of-recentrefugees-to-u-s/

Ramey, D. (2021, February 17). Ada County's median home sale price has tripled since 2011. Retrieved from https://www.ktvb.com/article/news/local/growing-idaho/ada-county-boise-housing-market-median-saleprice-increase/277-ec9cde22-1b0e-4c0a-935e-d9df6e2af1ab

Routley, N. (2020, October 23). Charting 20 Years of Home Price Changes in Every U.S. City. Retrieved April 23, 2021, from https:/www.visualcapitalist.com/20-years-of-home-price-changes-in-every-u-s-city/

Seattle Department of Construction and Inspections. (n.d.). Codes. Retrieved from https://www.seattle.gov/sdci/codes

Steven, E. M. (n.d.). A Comparison of Residential Tenancies and Unlawful Detainer in Idaho and Washington State (Working paper). Spokane, WA: Real Property Probate and Trust.

Supply and Demand, Markets and Prices. (n.d.). Retrieved from https://www.econlib.org/library/Topics/College/supplyanddemand.html

Thomas, T. A., \& Crowder, K. (2017). Forced out: Race, market, and neighborhood dynamics of evictions (Doctoral dissertation, University of Washington, 2017) (pp. 1-112). Seattle, WA: University of Washington.

Warren, K. (2019, December 11). 4 days in the fastest-growing city in America: Microbreweries, millennial transplants - and locals who are already afraid of getting priced out. Retrieved from https://www.businessinsider.com/boise-idaho-fastest-growing-city-in-us-photos-growth-cost-201912\#: :text=Boise saw an $18.2 \%$ population,city to buy a house.

\section{Bibliography}

Annunziata, S., \& Lees, L. (2020). Displacement and Discrimination: 'Evictability' of Refugees in Revanchist Rome. ACME: An International Journal for Critical Geographies, 19(1), 377-384. Retrieved May 11, 2021.

Bringhurst, T. (2020, July 31). Covid-19 is Worsening Idaho's Eviction Crisis. Retrieved May 11, 2021, from https://www.idahopress.com/boiseweekly/news/local_and_state/covid-19-is-worsening-idahos-evictioncrisis/article_92b71cdf-96ab-506d-9301-9066ebd44d1c.html

Chapple, K. (2016). Income Inequality and Urban Displacement. New Labor Forum, 26(1), 84-93. doi:10.1177/1095796016682018

Desmond, M. (2014). Relational ethnography. Theory and Society, 43(5), 547-579. Retrieved May 11, 2021, from https://www.jstor.org/stable/43694733?seq=1.

Desmond, M., \& Kimbro, R. T. (2015). Evictions Fallout: Housing, Hardship, and Health. Social Forces, 94(1), 295-324. doi:10.1093/sf/sov044

Desmond, M., Gershenson, C., \& Kiviat, B. (2015). Forced Relocation and Residential Instability among Urban Renters. Social Service Review, 89(2), 227-262. doi:10.1086/681091

Desmond, M., \& Gershenson, C. (2017). Who gets evicted? Assessing individual, neighborhood, and network factors. Social Science Research, 62, 362-377. doi:10.1016/j.ssresearch.2016.08.017

Desmond, M. (2019, March 01). Evictions: A hidden scourge for black women. Retrieved May 11, 2021, from https://www.washingtonpost.com/posteverything/wp/2014/06/16/evictions-hurt-black-women-as-much-asincarceration-hurts-black-men/

Donley, A. M., Crisafi, D., Mullins, A., \& Wright, J. D. (2017). How Stable is the Condition of Family Homelessness? Society, 54(1), 46-55. doi:10.1007/s12115-016-0099-0 
Eckart, K. (2020, February 10). UW study reveals gender, racial disparities in evictions. Retrieved May 11, 2021, from https:/www.washington.edu/news/2020/02/10/uw-study-reveals-gender-racial-disparities-inevictions/

Greenberg, D., Gershenson, C., \& Desmond, M. (2016). Discrimination in Evictions: Empirical Evidence and Legal Challenges. Harvard Civil Rights- Civil Liberties Law Review, 51(1), 115-158. Retrieved May 11, 2021.

Hall, M., Crowder, K., \& Spring, A. (2015). Neighborhood Foreclosures, Racial/Ethnic Transitions, and Residential Segregation. American Sociological Review, 80(3), 526-549. doi:10.1177/0003122415581334

Harding, H. (2020, September 10). The CDC froze evictions. How that could just make more problems for Boisearea renters. Retrieved May 11, 2021, from https://www.idahostatesman.com/news/rebuild/article245603715.html

Henly, J. R., Danziger, S. K., \& Offer, S. (2005). The contribution of social support to the material well-being of low-income families. Journal of Marriage and Family, 67(1), 122-140. doi:10.1111/j.00222445.2005.00010.x

Marcuse, P. (1985). Gentrification, Abandonment, and Displacement: Connections, Causes, and Policy Responses in New York City. Journal of Urban and Contemporary Law, 28, 194-240. Retrieved May 11, 2021, from https://openscholarship.wustl.edu/law_urbanlaw/vol28/iss1/4/.

McCoy, T. (2018, November 14). Eviction isn't just about poverty. It's also about race - and Virginia proves it. Retrieved May 11, 2021, from https://www.washingtonpost.com/local/social-issues/eviction-isnt-justabout-poverty-its-also-about-race--and-virginia-proves-it/2018/11/10/475be8ae-d7bd-11e8-aeb7ddcad4a0a54e_story.html

Soederberg, S. (2018). The rental housing question: Exploitation, eviction and erasures. Geoforum, 89, 114-123. doi:10.1016/j.geoforum.2017.01.007

Stabrowski, F. (2014). New-Build Gentrification and the Everyday Displacement of Polish Immigrant Tenants in Greenpoint, Brooklyn. Antipode, 46(3), 794-815. doi:10.1111/anti.12074

Zewde, N., Eliason, E., Allen, H., \& Gross, T. (2019). The Effects of the ACA Medicaid Expansion on Nationwide Home Evictions and Eviction-Court Initiations: United States, 2000-2016. American Journal of Public Health, 109(10), 1379-1383. doi:10.2105/ajph.2019.305230 